Case Study

\title{
CEREBROPROTEIN HYDROLYSATE INDUCED SYSTEMIC INFLAMMATORY RESPONSE SYNDROME (SIRS): A CASE REPORT
}

\author{
TARALI DEVI ${ }^{1}$, SUBHASH SARMA ${ }^{2}$, URMI CHOUDHURY ${ }^{3}$
}

1Department of Pharmacology, Assam Medical College, Dibrugarh, Assam, ${ }^{2}$ Department of Medicine, MABH, Dibrugarh, Assam, ${ }^{3}$ Department of Pharmacology, Assam Medical College, Dibrugarh, Assam

Email: drtaralidevi@gmail.com

Received: 10 Sep 2016 Revised and Accepted: 23 Nov 2016

\section{ABSTRACT}

Cerebroprotein hydrolysate is a newer pharmacological neurotropic agent and considered as a promising therapeutic agent for dementia, Alzheimer's disease, traumatic brain injury and acute ischaemic stroke. Studies revealed that most of the side effects are minor. Here, we reported a case of Systemic inflammatory response syndrome (SIRS) probably due to use of Cerebroprotein hydrolysate in a patient with acute ischaemic stroke.

Keywords: Cerebroprotein hydrolysate, Dementia, ischaemic stroke, Systemic inflammatory response syndrome

(C) 2017 The Authors. Published by Innovare Academic Sciences Pvt Ltd. This is an open access article under the CC BY license (http://creativecommons.org/licenses/by/4. 0/) DOI: http://dx.doi.org/10.22159/ijpps.2017v9i1.15138

\section{INTRODUCTION}

Cerebroprotein hydrolysate is a newer pharmacological agent which is reported to be neurotropic in nature and manufactured synthetically by the standardised enzymatic breakdown of lipid-free porcine brain proteins. It has been reported that cerebroprotein via certain mechanism enhances neurogenesis, neuronal survival and neuronal plasticity and also has neuro immunotropic mechanism of action [1]. By improving the metabolism of neuron and protecting nerve damage studies have shown cerebroprotein hydrolysate to be useful in vascular dementia, Alzheimer's disease, traumatic brain injury, acute ischaemic stroke and extrapontine myelin lysis [2-4] Cerebroprotein hydrolysate augmented proliferation, differentiation and migration of adult subventricular zone (SVZ) neural progenitor cells resulting in increased number of neural progenitor cells and neuroblasts to contribute to neurogenesis. This may be the mechanism for beneficial effect in acute ischaemic stroke and traumatic brain injury [5]. Studies have revealed that most of the side effects are minor. Most commonly headache, nausea, vertigo, increased sweating, agitation, fever, flu-like syndrome, hallucination, confusion, etc have been reported. It is contraindicated in hypersensitivity, epilepsy and severe renal impairment and used with caution in pregnancy and lactation [6].

\section{CASE REPORT}

A 52 y old female patient, known hypertensive and diabetic was hospitalised for the sudden weakness of the right side of the body for last $2 \mathrm{~d}$ and was diagnosed to be an acute ischaemic stroke. Plain MRI of the brain revealed acute ischemic infarct in (L) corona radiate with the affection of left frontal lobe white matter. All other routine investigations including routine blood, blood biochemistry, routine urine,chest x-ray, ECG, USG abdomen are within normal range. She was clinically stable without having any evidence of infection. She was administered with standard medications (injection mannitol, pantoprazole, piracetam, methylcobalamin, insulin and telmisartan). Next day injection Cerebroprotein hydrolysate $60 \mathrm{mg}$ intravenously once daily was added. On $2^{\text {nd }}$ day patient was getting better with stable vitals. Her blood pressure was around 160-170 mmHg systolic and 90-100 mmHg diastolic. After $2^{\text {nd }}$ dose of cerebroprotein hydrolysate patient suddenly developed a fever with chill and rigor and hypotension (systolic BP lowered to 80 $\mathrm{mmHg}$ ). Injection Cerebroprotein hydrolysate and all other relevant medications were immediately stopped and the patient was managed in ICUwith IV fluids, inotropes and dexamethasone injection and antibiotic-pipericillin tazobactam. On the day of admission WBC count was 8800/cumm and ESR 35 mmAEFH; after a patient had developed fever and hypotension $\mathrm{WBC}$ count raised to 28100/cumm and ESR 95 mmAEFH, CRP $123.2 \mathrm{mg} / \mathrm{l}$, Procalcitonin level was $91.09 \mathrm{ng} / \mathrm{ml}$. Following treatment of shock on the very $2^{\text {nd }}$ day patient was absolutely normal with normal vitals. BP raised up to baseline value and laboratory parameters returned to normal values (WBC count-5500/cumm, ESR 35 mmAEFH and CRP $27.1 \mathrm{mg} / \mathrm{l}$ )

\section{DISCUSSION}

Neurodegenerative disorders are one of the leading causes of death and disability in both developed and developing countries. Many neurotrophic drugs are developed and used. Cerebroprotein hydrolysate is the latest neurotrophic drug launched. Its superiority over other neurotrophic agents is because of its different mode of action which helps in faster and more complete nerve repair and growth. It consists of short biological peptides which act like endogenous neurotrophic factors. It is given in a dose of $60-180 \mathrm{mg}$ once daily for 10-20 d by slow intravenous infusion in $250 \mathrm{ml}$ saline over 60-120 min. Neurotrophic activity can be detected up to $24 \mathrm{~h}^{*}$ after a single injection [7]

Several studies have revealed minor adverse effects. Guo Wei Yan et al. confirmed allergic manifestation with the use of preproprotein hydrolysate injection [8]. Our patient developed sudden symptoms of SIRS after $2 \mathrm{~d}$ of drug administration which immediately improved after discontinuation of the drug and proper management. Dramatic development of shock and dramatic improvement after discontinuation of the drug within $48 \mathrm{h*}$ made us think that it might be due to the adverse reaction of cerebroprotein hydrolysate.

The casualty assessment by World Health Organisation Uppsala Monitoring Center scale [9] and Naranjo's algorithm [10] score 6) showed a probable relationship between the drug and the reaction.

Though rare, clinicians must be aware of such reaction in order to ensure timely diagnosis and treatment. Cerebroprotein hydrolysate is still in its nascent stage and will need rigorous randomised controlled trials before its efficacy and safety is well established.

\section{CONFLICT OF INTERESTS}

\section{Declared none}

\section{REFERENCES}

1. Bae CY, Cho CY, Chok, Hoon oh B, Choi KG, Lee HS, et al. A double-blind placebo-controlled, multicenter study of cerebrolysin in Alzheimer's disease. J Am Geriatr Soc 2000;48:1566-71. 
2. M Phirke, A Bharati, AV Sausa, N Shah, S Sonavane. Cerebroprotein hydrolysate in the treatment of vascular dementia a case report. Int J Pharmacol Clin Sci 2014;3:75-8.

3. Karia S, Mahajan PT, De Sousa A. Cerebroprotein hydrolysate in traumatic brain injury. El Mednifico J 2014;2:34-5.

4. Karia S, Majlikar R, De Sousa A, Shah N. Cerebroprotein hydrolysate in the extra pontine myelinosis-a case report. Int ] Sci Res Publication 2014;4:1-2.

5. Jain N, Yadav S, Gayal M, Singal KK, Gupta P, Bansal M. Cerebroprotein hydrolysate: Inoovation in neurodegenerative disorders. Int J Med Dental Sci 2014;3:132-3.

6. Arun Oommen. Cerebroprotein hydrolysate-new paradigm in the management of neurological problems. J Neurol Stroke 2015;2:76.

7. Praveen Gupta, Shailesh Yadav. Cerebroprotein hydrolysate: Innovation in the treatment of neurodegenerative disorders. J Indian Acad Clin Med 2014;15:132-3.
8. Guo Wei Yan, He Zong-Fang, WU Xin An, Chen Jun, Mao xiao, Guan Li, et al. Evidence-based analysis of a case with aggravating allergies after using multiple drugs in sequence. Pharm Care Res 2015;15:334-8.

9. The use of the WHO-UMC system for standardized case causality assessment. Uppsala: The Uppsala monitoring centre; 2005. Available from: http://www.who-umc.org/graphics/ 24734.pdf. [Last accessed on 05 Aug 2016]

10. Naranjo CA, Busto U, Seller EM, Sandor P, Ruiz I, Roberts EA. A method for estimating the probability of adverse drug reactions. Clin Pharmacol Ther 1981;30:239-49.

\section{How to cite this article}

- $\quad$ Tarali Devi, Subhash Sarma, Urmi Choudhury. Cerebroprotein hydrolysate induced systemic inflammatory response syndrome (SIRS): a case report. Int J Pharm Pharm Sci 2017;9(1):321-322. 